

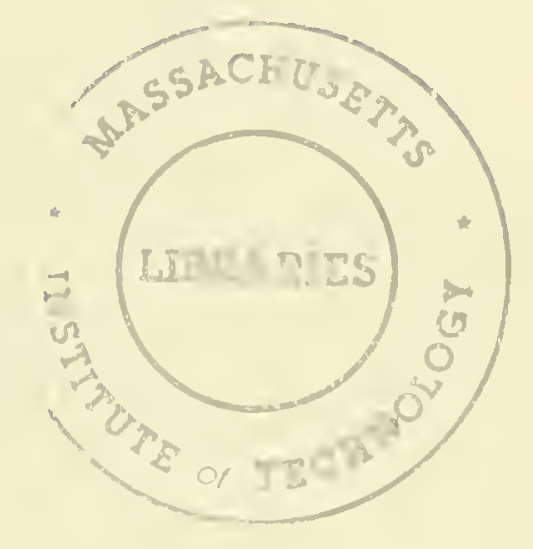




HD 28

no. 3270

91
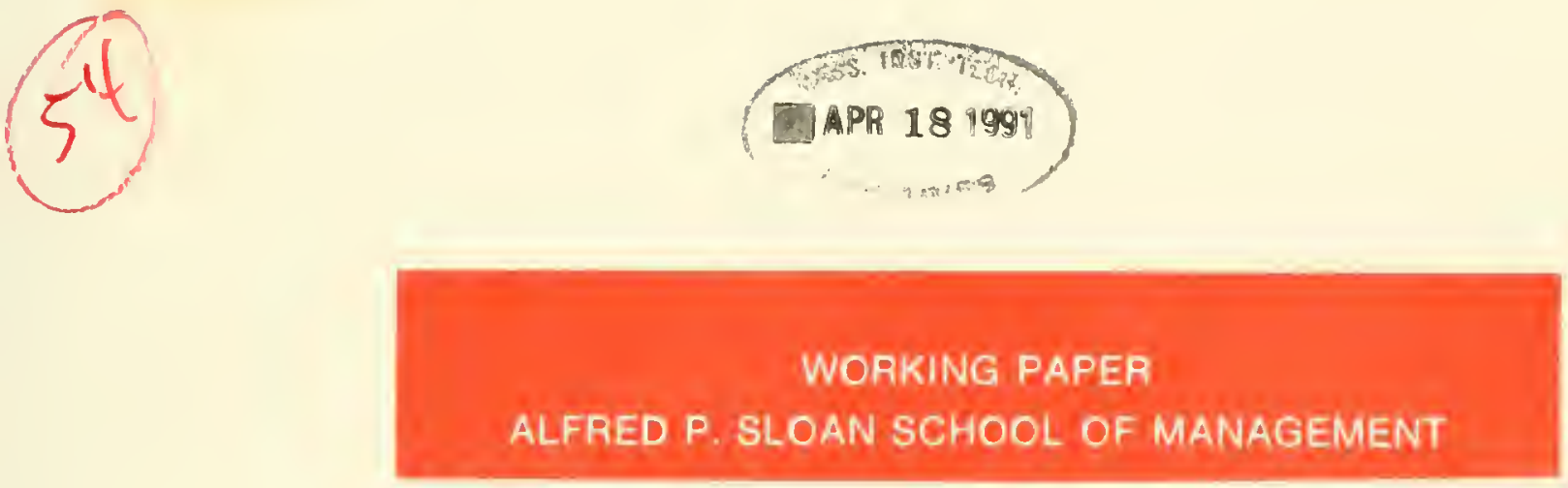

\author{
Wanda J. Orlikowski \\ Sloan School of Management \\ Massachusetts Institute of Technology \\ 50 Memorial Drive (E53-329) \\ Cambridge, MA 02139 \\ (617) 253-0443 \\ wanda@eagle.mit.edu
}

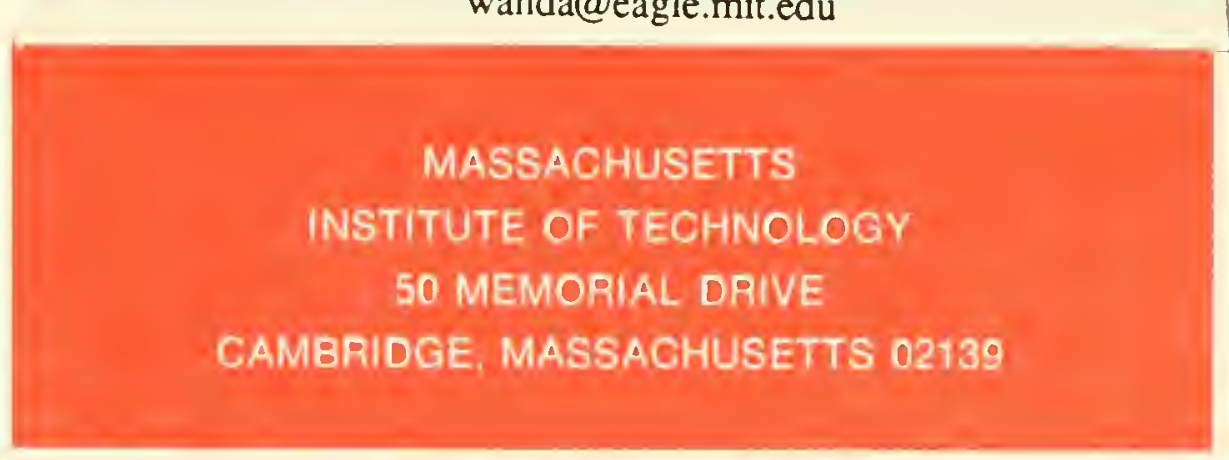




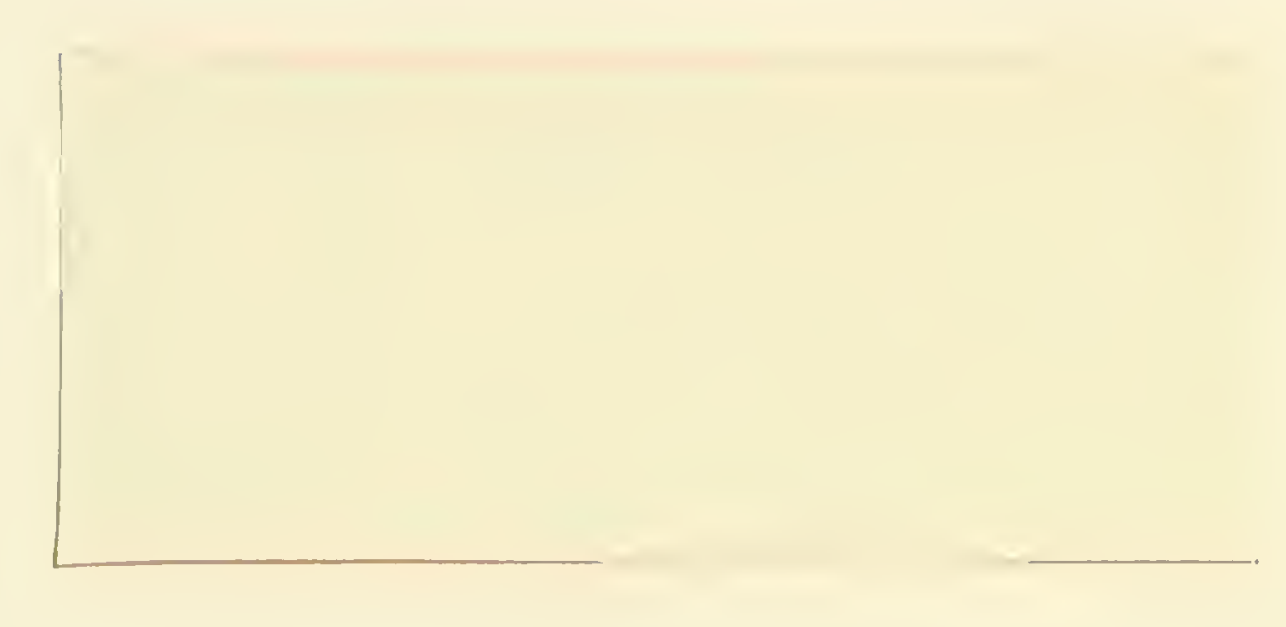




\title{
Integrated Information Environment or Matrix of Control? The Contradictory Implications of Information Technology
}

\author{
Wanda J. Orlikowski \\ Sloan School of Management \\ Massachusetts Institute of Technology \\ 50 Memorial Drive (E53-329) \\ Cambridge, MA 02139 \\ (617) 253-0443 \\ wanda@eagle.mit.edu
}

January 1991

Forthcoming in Accounting, Management and Information Technologies 


$$
\text { 四 }
$$




\title{
Integrated Information Environment or Matrix of Control? The Contradictory Implications of Information Technology
}

\begin{abstract}
This paper examines the extent to which information technology deployed in work processes facilitates changes in forms of control and forms of organizing. A field study of a single organization that implemented information technology in its production process is presented as an empirical investigation of these issues. The findings indicate that information technology reinforced established forms of organizing and facilitate 1 an intensification and fusion of existing mechanisms of control. While debunking the technological imperative once again, the results also provide a number of insights into the contradictory implications of computerbased work and control in organizations. In particular, the paper shows that when information technology mediates work processes it creates an information environment, which while it may facilitate integrated and flexible operations, may also enable a disciplinary matrix of knowledge and power. These findings and their implications for forms of control, forms of organizing, and professional practice are discussed.
\end{abstract}




\section{INTRODUCTION}

Much has recently been written about the potential of information technology to create new ways of organizing and transforming existing bureaucratic organizational forms and social relations [Applegate, Cash and Mills 1988; Drucker 1988; Hammer 1990; Huber 1986; McFarlan 1984; Miles and Snow 1986]. Many of these anticipated changes are premised on the potential of information technology to loosen the hierarchical stranglehold on organizational practices, creating networked and lateral relations that can usher in new organizational forms and practices. Among these potential forms we find cluster [Applegate, Cash and Mills 1988], information-based [Drucker 1988], networked [Miles and Snow 1986], post-bureaucratic [Toffler 1980], posthierarchic [Zuboff 1988], and post-industrial [Huber 1986]. Applegate, Cash and Mills [1988:136] write about their vision of the new organization: "The new technologies hold great promise that our large, rigid, hierarchies will become more adaptive, responsive, and better suited to the fast-paced world of the twenty-first century." While I do not deny the likelihood, in the long term, for transformation of the organizational forms prominent in advanced industrial economies [Heydebrand 1985, 1989], what remains largely unexamined in these sanguine speculations are the conditions and consequences of organizational change. In betting their hopes of organizational transformation on information technology, many of these commentators rely heavily--perhaps too heavily--on technological determinism.

To date, there have been few attempts to examine predictions about new organizational forms empirically (Hirschhom [1984] and Zuboff [1988] are two notable exceptions), and consequently there is little data on whether new organizational forms are indeed emerging, what their characteristics may be, and what intended and unintended consequences they may have for production tasks, skills, social relations, and control in the workplace. In this paper I discuss an empirical study that examined the relationship between organization control and information technology, a relationship which becomes particularly pertinent as more business processes are mediated by information technology. The results indicate that the mediation of work processes by information technology augments and extends existing mechanism: of control, while reinforcing established forms of organizing. Further, the information technology fuses together existing forms of control, creating an integrated information environment which has contradictory implications for forms of organizing and control--facilitating decentralization and flexible operations on the one hand, while increasing dependence and centralizing knowledge and power on the other.

The intention of this paper is to use the insights of this field study--which examined in detail the world of systems development within a consulting firm--to provide some understanding about possible control and organizing consequences of deploying information technology in work 
processes. The longer-term implications of these findings are also extended to other consulting and professional firms which are increasingly adopting information technology to mediate work processes. The insights gained here provide a grounded basis from which to continue empirical investigations of the implications of deploying information technology in organizations.

\section{FORMS OF CONTROL}

Organizations typically adopt a variety of control mechanisms to ensure that production work is performed in compliance with established plans, standards, quality criteria, and in conformance with organizational goals and values [Aldrich and Mueller 1982; Brewster 1986; Edwards 1979; Mintzberg 1979; Pennings and Woiceshyn 1987; Storey 1985]. Control mechanisms are understood to be both enabling and constraining: enabling in that they facilitate the coordinated action of individuals in the production process--what Boland [1979] termed "control with," and constraining as they restrict the manner and outcomes of individuals' actions--what Boland [1979] termed "control over."

In this paper, I focus on control in terms of the inclusion of workers in the production process, the definition of production knowledge, the execution of production tasks, and the conduct of employees in the workplace. Two forms of internal control and one form of external control are relevant to my empirical analysis. The following brief description of these forms of control is presented from the perspective of their implementors' intentions, and thus somewhat "idealistically." In practice, a great deal of negotiation around the meaning and effect of control mechanisms occurs in the workplace [Barley 1986; Burawoy 1985; Storey 1985, 1987].

\section{Internal Forms of Control}

Pennings and Woiceshyn [1987] examine various forms of internal control in organizations. Two are particularly useful to this discussion--personal and systemic control. Personal control is identified in terms of a dyadic relationship between supervisors and subordinates, having its usual expression in direct supervision where one individual assumes authority over the actions of others and closely monitors that action to ensure compliance with orders. Systemic control represents a shift from personal relations to more transparent, indirect, and impersonal forms of control, and is vested in three interrelated structural properties of organizations--technology, social structure, and culture [Pennings and Woiceshyn 1987:80].

In control through technology, control is embedded in the technical infrastructure of the production process. Control of work is built into the technology by engineers and system designers external to the production process. The archetypical example is the mass production assembly line, where 
workers' position in the production process determines the sequence and nature of tasks they execute, requiring them to adjust to the pace and rhythm of the machine. Control through technology changes the role of managers from direct supervision to enforcing the operation of the technical system.

In control through the social structure, control is embedded in a firm's policies, procedures, and rules, its well-defined job descriptions, career ladders, and incentive schemes. The standards and requirements for adequate job performance are explicitly set out, specifying what, when, and how production tasks should be accomplished. Production knowledge is embedded in bureaucratic procedures and employees' firm-specific skills. Task performance is evaluated according to specified and measurable criteria, hence managers' judgements of work achieve "objective" status and serve to reinforce the apparent neutrality of the policies, procedures, and nules.

In control through culture, workers' shared norms and values shape behavior, order perception, and influence attitudes [Bimberg and Snodgrass 1988; Knights and Willmott 1987; McDonough and Leifer 1986; Ouchi 1979; Ouchi and Johnson 1978; Pennings and Woiceshyn 1987]. A shared ideology obviates the need for extensive and explicit procedures and rules, providing a philosophy of interests and norms from which members can deduce an almost limitless number of specific rules to suit varying conditions. Workers are directed through having internalized the appropriate organizational norms during initial and ongoing socialization, a process that attempts to instill and reinforce goal and value congruence between individuals and those espoused for the organization.

\section{External Forms of Control}

Control of production knowledge and task performance may also have its roots outside of organizations. In addition to various forms of internal control that organizations may impose, they may also rely on professional control, in which they delegate a large part of the indoctrination and training of their specialist employees to outside institutions such as professional schools and occupational communities. Organizations resort to this form of control as production processes become complex and dependent on highly specialized skills and knowledge. Perrow [1986] notes that organizations can reduce their number of written rules (which typically cannot cater to the unpredictability of complex demands) by "buying" personnel who have complex rules built into them, and who can employ them in varying circumstances. The authority invested in individual professionals is based on the special occupational competence they apply under conditions of task uncertainty, risk, complexity, and variability, e.g., accountants, architects, engineers, or surgeons.

In professional control, production tasks are made to conform to the norms and standards of the 
profession, and the production process is controlled by the prescriptions of "professional practice." While production expertise is vested in the professionals, they are not fully in control of this knowledge, relying on their professional association for developing, articulating and disseminating it. Although they may modify the knowledge in application, they tend more usually to reaffirm it through invoking it to execute their production tasks. By employing professionals, organizations incorporate individuals whose training and orientation are gained outside of the firm, who have typically been certified by external licensing agencies, and whose allegiance to the organizations is often surpassed by their loyalty to and identification with their professions.

Systemic and professional forms of control can be seen as instances of Foucault's [1979] disciplinary power, in that control is exercised indirectly and impersonally through a range of institutional, technical, and normative regulations, and does not emanate directly or physically from individuals. Compared to the sovereign power it replaced--where power was exercised via a physical spectacle of force--disciplinary power is less visible, obscured by the apparent neutrality of knowledge, technology, or morality. Paradoxically, as disciplinary power becomes less visible, its object--individuals and their behavior--become more visible [Giddens 1982]. By complying with forms of systemic and professional control, workers unintendedly, reproduce the forms of control through which production tasks are shaped.

While a number of different control forms have been identified, it is common for multiple control mechanisms to coexist. As Storey [1985] suggests, control usually works in levels and cycles, so that if one level of control fails in an organization (say, technology control), then other forms (say, personal control) assume dominance. In any account of control, however, it is necessary to recognize that power relations are reciprocal in nature, hence they are not totally dominating. Discussions of organizational control often tend to downplay the extent to which individuals retain the potential to act to change a particular situation or form of control. This capability "to choose to do otherwise" is central to Giddens' $[1979,1984]$ notion of agency, which he refers to as the dialectic of control, noting [1984:16]: "All forms of dependence offer some resources whereby those who are subordinate can influence the activities of their superiors." How and when this dialectic is expressed, how sustained are its effects, and what the long-term implications for control and organizing are, are clearly empirical questions. Particular contexts and forms of control will induce their own brands of dissent, protest, and potential transformative action by workers.

\section{Information Technology and Forms of Control}

Informing this research are my assumptions about organizations and information technology which draw on Giddens' theory of structuration [Giddens 1979, 1984]. From this perspective--as I 
explore elsewhere [Orlikowski 1991]--structure exists only as it is instantiated in action, and information technology can be interpreted as an occasion for structuring organizations which both facilitates and constrains action. Agents in organizations draw on the rules and resources embodied within information technology in their ongoing execution of production tasks. Yet in their very use of this information technology--by orientating their practices around it--they unintendedly reaffirm its importance, form, and content, and reproduce those rules and resources as their organization's structural properties. They may also potentially change the technology and their organization, but this occurs less frequently.

By forms of control in organization, I mean the mechanisms by which "agents seek to achieve and maintain the compliance of others" [Giddens 1985:9]. In Giddens' analysis such forms of control are premised on and expressed through the asymmetrical distribution of resources [Cohen 1989:151]. Two kinds of resources are distinguished: allocative resources used to generate power over objects, and authoritative resources used to generate power over persons [Giddens 1979:100]. Giddens assigns technology to the allocative resource category and hence, by definition, the role of generating power (and control) over material phenomena. This distinction-albeit analytical--is somewhat misleading in that it implies that technology does not figure prominently in exerting command over r ztors. But technology--and particularly information technology--is intimately implicated in the structuring of actors' daily work through information storage, retrieval and transmission capabilities, through providing the means to accomplish tasks, through imposing a rhythm and schedule on the flow of computer-based work, through providing technical vocabularies to mediate meanings ascribed to events, objects, and relationships, and through coordinating activities over time and space [Orlikowski 1991]. I thus treat information technology as an administrative resource having both allocative and authoritative aspects, and as capable of significantly influencing the manner and form of control employed in organizations.

My intent in this paper is to explore how the introduction of information technology in production work changes the nature and role of organizat onal control mechanisms, and what are the implications--intended and unintended--for organizational forms and worker agency. The literature on new organizational forms suggests movement away from hierarchic and bureaucratic forms of control and organizing. On the other hand, the inertial force of established bureaucracies and the strategic importance of production processes might lead us to expect information technology to supplement rather than to undermine existing control mechanisms. In contrast to both these views, we could posit that the unprecedented nature of advanced information technology and its complex interaction effects [Perrow 1983] will generate contradictions which undermine organizational arrangements in unanticipated ways. In such contradictory developments, nonlinear change is 
possible [Ollman 1976], and organizational properties may be transformed so as to be substantially different from those that existed before, or even those imagined by organizational commentators. A number of eventualities are thus possible, and which prevail under particular organizational conditions is the research question explored below.

\section{RESEARCH STUDY: Methodology and Research Site}

The findings discussed here are part of a larger research study that focused on the changes that accompanied one organization's implementation of information technology [Orlikowski 1988a]. I studied a large, multinational software consulting firm, Software Consulting Corporation [SCC], which builds customized software applications for client firms across various industries such as financial services, manufacturing, retail, and government. The software developed by SCC typically consists of large, transaction-processing application systems that clients use to support their major administrative activities. In 1987, SCC earned $\$ 600$ million dollars in worldwide consulting fees and employed over 13,000 consultants in 200 offices distributed throughout 50 countries. SCC's operations are organized by project, with project teams varying from around ten to over a hundred personnel, and projects extending from a few months to a number of years in duration. Project costs range from a hundred thousand to a few million dollars.

While SCC is a major player in its industry, it experiences much competition from the major accounting firms, which have created separate divisions devoted to management advisory services including software development. Over the last two decades, as a consequence of the growing demand by clients for large, complex, integrated applications, SCC and its competitors have attempted to streamline as much of the software development process as possible. The most visible manifestation of this strategy was the decision by SCC management, about eight years ago, to construct and deploy information technology to automate its software development process. This process technology, known as Computer-Aided Software Engineering [CASE] technology in the software industry, is referred to as "productivity tools" within SCC.

My research methodology was a contextualized, interpretive one, employing the techniques of organizational ethnography [Agar 1980, 1986; Van Maanen 1979, 1988] over eight months. Data was collected via on-site observation of participants, unstructured and semi-structured interviews, documentation review, and informal social contact with the participants. Background and historical data on the SCC corporation and its systems development practices was gathered from published material (inhouse and trade press), and from interviews with senior managers who had been involved in SCC's traditional production process, as well as its adoption of automated production process. With some background information on SCC and its practice, five different application 
projects (four large and one small) were selected for indepth analyses. Projects were carefully identified to guarantee exposure to the use of productivity tools in all major phases of the systems development production process (requirements analysis, conceptual design, detailed design, implementation, and testing). An average of four weeks was spent on each project, observing and interviewing team members in their daily systems development work, and in their interaction with each other and the productivity tools. Data was also collected throughout the study at monthly (all day) division meetings, and in project training sessions on productivity tools. Participants spanned SCC's hierarchic levels from the most junior consultants and programmers, to senior project managers. Other key informants were identified and sought out both within and outside SCC, such as the director of research and development, senior recruiting officers, sales directors, major client managers, and former SCC employees.

\section{RESEARCH RESULTS}

The discussion of results articulates SCC's work practices and primary forms of control, and then examines how these changed with the implementation of information technology.

\section{Systemic Forms of Control: Hierarchy and Career Path}

SCC is a quintessential "knowledge-based" firm providing consulting services to its clients. It is organized along matrix lines, refl cting a stable consulting practice hierarchy and a more dynamic project team organization through which work is conducted. Except for office support staff, all employees are referred to as "professionals," with the practice hierarchy defining a single career path for all employees. The articulation and realization of this single career path is a central element in the firm's systemic form of control. The career path consists of a few, well-defined stages that all employees are phased through to enact the firm's defined track of "career development." Formalizing fine levels of career gradation serves multiple goals. It constitutes a planned management of individuals' activities over time, with different levels of work responsibility and training associated chronologically. This sort of temporal regulation of individuals is central to Foucault's notion of disciplinary powe-: He writes [1979:160]: "The 'seriation' of successive activities makes possible a whole investment of duration by power ... the possibility of characterizing, and therefore of using individuals according to the level in the series that they are moving through." The SCC career stages and their fixed terms are: junior consultant (two years), senior consultant (two years), manager (six to seven years), and senior manager. Second, career stages provide concrete signification of career progress for individuals for whom success on the job is equated with attaining and passing the requisite milestones. Thus, it officially recognizes and rewards them on having dedicated progressing numbers of years of their lives to SCC. Third, career stages formally differentiate employees by status, declaring difference and distance, and 
supporting micro-strategies for the play of power and authority. Finally, it allows SCC to bill clients more for employees' time. One manager explained: "They want to raise your charge-out rate, but to do that they must give you a new title, and then you look different to the client."

The SCC hierarchy is maintained by an "up or out" promotion policy, where tenure in the firm is associated with greater organizational standing. At the end of the appointed time in each stage, employees are evaluated for movement to the next stage. Failure to win promotion results in termination of employment, a process euphemistically referred to as being "counseled out of the firm." On project teams, the firm authority structure dictates the division of labor in the production process, with the project leaders (composed of at least one senior manager and one or more managers) coordinating the efforts of junior and senior consultants. Thus, status in the firm correlates with status on project teams, a few discrepancies being due to specialized experience with different business practices or technologies.

\section{Systemic Forms of Control: Production Knowledge}

When SCC first began consulting in the early sixties there were no formal standards or guidelines by which software consultants conducted their practice. Application systems were built by trial and error. Over time, a body of inhouse systems development knowledge accumulated through the sharing of experiences, and some informal checklists were compiled and circulated. But the software consulting practice kept growing (at a rate of about 150 percent annually) and SCC acquired more personnel and clients. The informal tradition with which SCC's practice guidelines were learnt and communicated was no longer adequate. The guidelines were too open-ended, assumed too much competence, and could not deal with exceptional conditions. Projects had become bigger and more complex, the stakes higher, and losses more severe and visible. In response, SCC managers set up a firm-wide task force to codify the informal systems development heuristics, expanding them where appropriate, and formally instituting an SCC practice methodology. The methodology prescribes a sequence of systems development stages, articulates the tasks and deliverables of each stage, defines the skills needed to perform the tasks, establishes guidelines for estimating time and budget requirements, and specifies quality controls and process milestones. In addition to specifying production tasks and techniques, the methodology embodies a particular philosophical orientation to the development of application software, known as structured systems analysis and design [DeMarco 1979; Yourdon and Constantine 1979].

SCC's methodology underlies all of its production processes. In fact, the activities of SCC project teams cannot be fully understood without reference to the methodology. Consultants, from all levels in SCC, refer to it as "our bible." The formalization and standardization of the methodology 
constitutes a cornerstone of disciplinary practice, a means of controlling processes and results [Foucault 1979:137]. It is a way of imposing an "order" on consulting practice, and is "both a technique of power and a procedure of knowledge" [Foucault 1979:148]. SCC's deep-seated commitment to using a standardized development approach is an aspect of its ideology as well as its strategy. In terms of SCC ideology, that the firm uses a single, uniform methodology throughout the world allows it to claim consistent, quality service to all clients, and capable of staffing a project at short notice. A senior manager expressed this rationale:

In SCC we believe that you should be able to field a team at a moment's notice, and that the team members should be effective in two hours. And we can do that because all our people speak the same language, have the same training, and share the same experiences. They've even heard the same war stories passed on from the trainers, our senior people in SCC. So we have a small army that can do things the same way, and they all have highly predictable expectations about SCC and the work.

The uniformity afforded by the methodology was, for some, cause for humor. A manager noted:

We have a famous saying about this: They send you halfway around the world and because of the common way of doing things and the common training and knowledge, your only requirement is to be shown the coffee machine and the toilet, and you're productive.

Before the implementation of productivity tools, SCC's standardized methodology provided the primary production knowledge. To the extent that consultants conformed to the methodology, it served as a form of systen.ic control. While younger consultants and recently promoted managers tended to interpret the methodology literally, and follow its procedures "to the letter," other more experienced employees seemed less constrained, relying on their initiative to direct production work, and using the methodology primarily as a coordination device to manage impressions through appropriate behavior packaging. Thus, while the methodology is prescriptive in documentation, in practice, its tenets were often modified, overridden, or ignored.

Even while SCC's methodology represents a corporate endorsement of standardized production procedures and rules, it appears that before productivity tools, consultants and managers were able--within limits--to use their discretion in when and how to apply the methodology. This mechanism resembles professional control in that the individual practitioners were given autonomy to determine how to proceed in a given production situation. The mechanism differs from professional control, however, in the locus of professional expertise. While professional practitioners apply significant discretion over production processes, they do so on the basis of a knowledge base that is largely independent of their employing organization. As certified professionals their practice is circumscribed by the standards, rules, and methods of their profession. Notwithstanding the tendency in the computer industry to label software personnel "professionals," and even though SCC calls its consultants "professionals," the work performed 
by SCC consultants is not affiliated with a clearly recognizable, external institution. There is no formal, officially sanctioned "data processing" or "software" profession, which trains, licenses, represents, and protects its members [Orlikowski and Baroudi 1989]. Unlike professional practitioners, SCC consultants and managers do not have "rules built into them" by pre-SCC professional training, and so they are not bound to follow the production standards, methods, and norms of an extrinsic, institutional body.

\section{Systemic Forms of Control: Socialization}

Cultural control in SCC is largely accomplished through workers' internalization of SCC's assumptions, values, and interests. Socialization helps individuals internalize those assumptions and beliefs that inform shared norms and perspectives [Schein 1987] so as to be able to apprehend the world in a meaningful way; meaningful that is, in that it corresponds to the dominant assumptions of the firm. Socialization, in particular, is the acquisition of role-specific language and knowledge, which structure conduct and interpretation in an organization [Berger and Luckmann 1967]. Through acquiring a language the various interpretive schemes operating in the organization are learnt and internalized, along with legitimate and normative modes of being in the institutional context. Role-specific language with its vocabulary, images, and relations thus transmits more than just a medium within which to perform a role. It also shapes the content of that role by determining the meaning of role experiences and by defining what actions are permissible, and which are not. That is, it is not only a model of action, but a model for action and a framework for legitimizing that action [Feldman 1986; Geertz 1973].

I have already mentioned the extensive socialization and training received by the consultants while at SCC. SCC is distinctive among its competitors in that it almost exclusively hires personnel straight out of college. Over 99 percent of the people hired into SCC are entry level, with an average starting age of 22 years. The training given each employee within SCC is considerable and expensive. In 1987, SCC spent about $\$ 60$ million (about ten percent of revenues) on "professional training." SCC employees spend over 1500 hours attending in-house training courses in their first six years. Socialization begins early, in the recruiting activities of the firm. SCC's recruiting process is very selective, some would say elitist, as reflected in an SCC recruiting brochure:

As you enter the recruitment process of SCC, you enter a world where success is expected. Your peers will be among the best in their class. Your past experience, your record, your general image will be carefully scrutinized. We are very careful in selecting our professionals because we want to make sure the match is right--for you and for us.

and these statements by senior managers:

Our philosophy is to take the best raw material we can find, and send them through several levels of screening. So we're very selective. We have a series of very intensive interviewing 
stages. But this way we're trying to make sure we take the top one percent of all college graduates.

We don't like to hire people with experience, as we feel that three to four years of SCC experience is better than ten to twelve years of experience elsewhere.

When we get the best people from the best schools we know we are getting the best possible candidates, the cream of the crop, and we are also getring as unmolded a talent as possible.

The notion of molding raw material is particularly central to SCC which invests heavily in socializing individuals into "the SCC way" (see below), and hence prefers business novices. A senior manager provided a religious analogy:

Our philosophy on training is just like the Catholic Church doctrine on training. What is that again? Give me a child for the first seven years of his life and I will give you the man? Well here at SCC we say, "Give us a young person for the first few years of their [sic] career and we'll give you the professional."

SCC consultants are exposed to extensive training and socialization within SCC. From the moment of their entry into SCC, when they spend six weeks in initial orientation and training, throughout their careers as consultants and managers, employees undergo SCC's version of "professional training" in internal and on-the-job training. An SCC recruitment brochure informs its readers that: "By the time you advance to manager, you will have developed the technical competence of an information professional." Thus, in practice, SCC's indoctrination and training effectively controls the decision-mi cing premises of the consultants in a manner similar to professional norms among professionals, resembling external forms of professional control. But, rather than the more eclectic and theoretically-based knowledge and skills generally associated with professions, consultants learn the techniques and standards of SCC's exclusive approach to systems development. Once acquired by consultants, this approach is reinforced by them through its application on projects.

The selective recruitment and extensive socialization of personnel suggests once again that, despite its claims, SCC is not in the conventional sense of the term, a professional firm. It does not hire professionals out of professional schools who have been certified by external institutions. Rather, through its training ant socialization program it breeds its own "SCC professionals." In contrast, thus, to professional practitioners who acquire knowledge of a professional discipline and practice in an environment independent of any organization, SCC consultants acquire systems development knowledge within the social and cultural environment of SCC. This has significant implications for their ability to decouple their view of production from "SCC's view of production." In fact, as far as many of the consultants are concerned, the two are synonymous. Before productivity tools were introduced, the primary role-specific language that consultants learned was SCC's methodology. A senior manager admitted: "All the steps of the methodology are built into my thinking; it's part of how I work; it's part of our culture, our lifestyle," while a senior consultant noted: 
We do use it [the methodology], in fact more than we know. We don't realize how much we depend on it. So we tend to believe it more. I don't think about the methodology I just do it. I don't think I realized what I was learning when I learnt [the methodology]. We teach it a lot to all the new people in the first few years. So they are not aware of how much they have learnt. And that's good because the methodology is built into people without them actually knowing it.

To the extent that consultants are unable to reflect on the practice of their work independently of SCC's methodology, they are subject to a form of cultural control, "ideational control," where control is implicit in workers' compliance to a symbol system [Czarniawska-Joerges 1988; Rosen and Baroudi 1987]. A few consultants and managers--usually the more experienced ones--are able to conceptually disentangle production work from the role-specific vocabulary they use to describe it. For such consultants, ideational control is less effective.

\section{Systemic Forms of Control: Impression Management}

Within SCC the processes of socialization instill a sense of appropriate behavior, which comprises another significant area of cultural control--control of conduct. Comments by a manager and a senior consultant convey this form of control:

The recruitment of graduates straight from college ensures that they have no other experience of other organizations, or other ways of doing things, or other peoples' expectations. SCC gets them so very young that they don't know anything, and so SCC defines for them what it is to be a professional. So that is all they know.

The most useful thing about the schools is that they indoctrinate you into SCC culture, which basically translates into: work hard and be professional. What I mean by the latter is that you soon realize that professional demeanor, conduct and appearance are very important. For example, look around you. Do you see anyone from SCC who is not well-dressed? Do you see anyone who is fat? Did you notice that all the men are clean-shaven? All this is not a coincidence.

The image that the consultants project is very important as they are constantly "on-show" as it were, conducting their production work publicly in client sites, subject to the scrutiny of clients at all times. Goffman's [1959:107] notion of front and back regions recognizes that different locales are ordered by different moral and instrumental requirements of decorum, which are typically internalized, and hence taken for granted by the participants. The consultants work in a space that is always "frontstage" and they rarely retreat "backstage" during their working hours. Even when not at client sites, say when they are travelling, consultants are still in the front region, because they are in the presence of potential clients. They are expected always to remember that they are representatives of SCC, and that their conduct reflects on their firm. At any time (including social time) they may be observed by other members of SCC, who have the obligation to report on their conduct if it is considered unbefitting. These informal, impromptu reviews are sufficiently important and frequent that they have been formalized. A special form known as a "greensheet" is available at every office for capturing the details of such incidents, and once completed is kept with 
the more formal reviews in an employee's file at the local office. By controlling the definition of the setting which employees inhabit, SCC can control their conduct. The demand that consultants are constantly in the front region is thus a more subtle but no less important aspect of SCC's control mechanisms. This form of control begins to resemble emotional labor, which Hochschild [1983:7] defines as labor which "... requires one to induce or suppress feeling in order to sustain the outward countenance that produces the proper state of mind in others."

One aspect of frontstage requirements is personal appearance. Whatever the state of affairs of the project, the appearance of competence must always be maintained, hence consultants are required to dress professionally, to take care of their physical appearance, and to appear competent, enthusiastic, and energetic at all times. Conformity in dress is very apparent. One former manager reported that when he left SCC, people would often asked him what he was going to do next. His standard response was: "grow a beard." The dress and appearance codes while not explicitly enforced, were enforced by exception, so that if someone stepped out of line they were reproved. A manager reported that one of his colleagues was taken to task for carrying a briefcase that "looked too ostentatious," and a senior consultant recounted how having gained twenty pounds over a few months he was reprimanded by his manager and advised to have shed the excess weight by his next evaluation in three months.

SCC consultants work large amounts of overtime. Extending the length of the working day was a regular means of employee control in the industrial era. It appears to be equally effective in professional practice and consulting firms of advanced industrial economies. Overtime work is often required because project schedules are tight, although there are also other, more symbolic, reasons. Overtime work serves as a particularly useful device of impression management in the front region. One senior consultant, working on average more than fifty hours a week, noted:

Some of the overtime we do is face-time. That is, even if we are not needed we have to hang around and find stuff to do. This is both to show your manager that you are dedicated and for the client to think he is getting his money's worh.

while a manage "explained:

If they [SCC senior managers] ask you to work overtime, you wouldn't dream of refusing as that would be seen as "unprofessional," and as if you were questioning their judgement. So no one dares to refuse, even if it is not really necessary. You just can't be seen to put your personal life before SCC.

Another manager noted that he was embarrassed to record on his time sheet that he had only worked ten hours a day. He was concerned that this would be perceived by his manager and his peers as "shirking" and as not being fully committed to the firm. The dedication expected of employees characterizes high achievement corporations, and is seen as a central component of appropriate "professional" conduct. 
An aspect of frontstage impression management akin to "face-time" is one I term "make-expert" which refers to individuals passing themselves off as experts when they may not be. A former manager described some internal tension he had experienced when his expertise was inappropriately represented to clients:

What I hated most was when they [SCC senior managers] sold me off as an expert on something when I didn't know anything about it. For example, I was a manager on a manufacturing job in [a midwestern state] doing a "just-in-time" system. I had never designed and installed one of these before, but everyone at the client was told that I was the SCC "just-intime" expert. That puts a lot of pressure on you. I just didn't like it. I was sure I could do the job, but I just don't like having to pretend to be something I am not. They had to pass me off as an expert as they were charging such high rates for me, $\$ 200$ an hour. That's more than $\$ 2000$ a day. And I was only getting paid just over $\$ 40,000$ per annum.

This presentation of employees to clients as something more then they are, is practiced routinely by SCC. The tactic is usually successful because of the high calibre of the people recruited and the rigorous review process imposed on projects. However, the effect on the individual managers and consultants is to intensify their efforts to work harder and longer, not only because they personally want to do a good job and because they feel obligated to meet the client's expectations, but also because they know they will be evaluated on the outcome of the current project--an evaluation process that is not charitable to failure. These various tactics of impression management [Goffman 1959] constitute effective forms of cultural control, as well as examples of Foucault's [1979] disciplinary matrix, in which individuals come to participate in their own examination and normalization [Boland 1987; Miller and O'Leary 1987], that is, "subjects whose very sense of normality and individuality is dependent upon, and supportive of, the reproduction of the prevailing forms of domination" [Knights and Willmott 1987:47].

Reinforcing SCC's ideology of professionalism is the notion that SCC employees are special. There is a wide-spread belief among SCC consultants and managers that their firm has hand-picked the top candidates in the country to work for SCC, and this is reflected in and sustained by the corporate self-image that suggests that SCC too is "best of breed." This self-image of the firm and of employees is a critical element of the corporate culture and is reinforced constantly, through training, SCC meetings, internal SCC documentation, relationships with peers, superiors, and clients. The easiest way to reaffirm this notion is to require individuals to live it out, that is, for consultants to enact the notion that they are special, different, and exceptional, as these consultants do every day in their encounters with clients where they are usually cast in a superior role--"the experts"--and constantly deferred to (at least in the clients' frontstage). A belief that one is among "the best there is" not only endows an individual with a sense of importance, it also generates feelings of identification with and allegiance towards the institution that has so acknowledged one. 
It further guarantees a high level of work achievement. Everyone is trying to demonstrate excellence, and--given the competitive nature of the promotion process--outdo or outperform one's peers. One senior manager indicated:

We have an exceptionally strong culture in SCC which encourages people to push themselves and work haru. The people we get are used to being top of their classes, so when they join SCC, they get a bit of a shock. They are humbled when they see the group they are with, their peers, who are all very smar, all in the fast track. So you see a lot of peer group pressure. They think, "I'll have to hussle to show my wares; I'll have to work real hard to keep up with those other guys." All the individuals in our firm are highly motivated and ambitious, and in SCC there's always more to strive for, first promotion, then to make senior manager, and then to get more units of ownership.

After a while, impression management and presentation of self become a way of life, so that being "in character" becomes a self-fulfilling prophecy. By acting out the role of assertive, competent, professional business persons--and being reinforced in doing so by peers, superiors, and clients-these young consultants become the competent professionals they believe they are.

The recursive influence of impression management is also evident at the level of the firm, where SCC acts out the role of the "industry leader" it has attributed to itself. A senior manager observed:

As employees in SCC, we are proud that we make up part of the less than five percent of the world who are decision makers. ... I tell my people, be proud that you are one [sic] of the few people who help make the world tick.

Revealed here is the mechanistic manner in which SCC views the world, as machine-like, a mechanism engaged in "ticking" action, action that is regular, predictable, exact, technical, and instrumental. Also revealed, is the role SCC sees for itself within that world, as enabling and sustaining the mechanistic process. Seen in this light, the formalized and disciplined methodology created and sustained by SCC practice is both the medium and the outcome of SCC's mechanistic vision of the world. It helps SCC respond to and shape the world mechanistically, even as it shapes SCC internally and recursively in this mechanistic image.

\section{Personal Form of Control: Direct Supervision}

Desp.te the imposition of the systemic forms of control discussed above, SCC project members are also subject to personal control to ensure appropriate production outcomes. Project managers employ a high degree of direct supervision by reviewing all the work done by consultants, and insisting that senior consultants review junior consultants' work. Reviews attempt to ensure that the work conforms to the methodology, meets established quality criteria, and does not exceed project-defined schedules. In general, the level of supervision on a project is relatively extensive for personnel who are billed out as professionals. A junior consultant, who had worked in other organizations before SCC, remarked:

I have found that in SCC the checking and review is much more than elsewhere. You always 
have someone - either a senior [consultant] or a manager - looking over your shoulder. It's for quality control, to make sure that the product delivered is good. ... We even have a joke about this: How many SCC people does it take to xerox a document? Answer: Two, one to press the button, and the other to look over his shoulder.

This degree of monitoring is particularly time-consuming and it is a disincentive for task delegation. A number of senior consultants mentioned doing more work themselves rather than delegating it. The pressures on senior consultants are high, particularly those close to being considered for promotion to manager. They are held accountable for the work done by the junior consultants they supervise, and so they expend much effort ensuring the work for which they are responsible is done properly. One newly promoted manager suggested that this was the way SCC increased the amount of work obtained from consultants. ${ }^{1}$

\section{Integrating Personal and Systemic Forms of Control: Direct Supervision}

Direct supervision also operates through regular reviews of individuals and projects, an integration of personal and systemic forms of control. Throughout their careers with SCC, individuals are evaluated regularly. They receive formal reviews from their immediate supervisors on projects every three months and a formal promotion review from the senior managers in their local office once a year. ${ }^{2}$ The reviews are done by the supervisor completing a standard evaluation form-referred to as a "Counseling Form"--comprised of two parts, a predefined set of questions, and topic headings with space for free-form comments. There are 56 pre-set questions dealing with five areas of competence: analytical ability, job administration, communication skills, professional and personal qualifications, and supervisory skills. For each of the questions the supervisor evaluates individuals by comparing their performance to what would typically be expected from a person of comparable seniority, skills, and experience. A checkmark is placed next to the question, in one of three columns, "Exceeds," "Meets," and "Less Than," to indicate how individuals rate against the "standard." Free-form questions deal with the same five areas and some others, such as "General Business Skills," "Business Awareness," and "Key Areas for Development" where the supervisor is told to "Identify at least two areas for development." In general, evaluations are heavily oriented towards professional conduct and supervisory skills, and appear to play a central role in individuals' promotion and tenure in the firm. They suggest the hierarchical surveillance, perpetual assessment, and continuous classification techniques of Foucault's [1979:220] disciplinary power, embodying a normalizing judgement and corrective intention which "... compares, differentiates, hierarchizes, homogenizes, excludes. In short, it normalizes" [Foucault 1979:183].

1 a form of labor intensification [Marx 1977].

2 Many of the consultants I spoke with reported occasional slippages when the quarterly reviews were not done on time, or not done at all. Because of the amount of work required by a supervisor to complete the evaluation form--one senior consultant reported spending ten hours per evaluation--it is no surprise that the pressures of project work take preference over reviews. 
Project reviews are formal inspections of projects' progress, every three months or so, by senior SCC managers not otherwise connected with the projects. These QA [Quality Assurance] managers carry the mandate of SCC in ensuring that the project process and outcomes comply with SCC's standards for production work, and that the project team members act within the bounds of acceptable practice. This form of personal control interacts with systemic control in that the manner of a QA is formalized in the methodology, which also outlines the specific aspects of a project to be reviewed. ${ }^{3}$ Project reviews are stressful times for a project team, as evinced by the behavior of project team members anticipating the onset of a project review. I observed this on two projects that experienced reviews during my visits. In each case, the project became a hive of frenzied activity--significantly more so than usual--the week or two prior to the anticipated review. Everyone rushed to complete tasks and documentation so that they could appear to be on schedule. Knowing the extent and content of the upcoming review, the project team members knew what level of completeness was required. Standards were complied with and documentation was completed. Almost all the consultants worked overtime. Tempers flared, and people were irritable. I was told to stay out of the way. The general sentiment was that the review process is "always a pain." The sense of relief on the projects in the days following a successful review was palpable.

In detailing the motivation for and conduct of individual and project reviews, SCC senior managers and the methodology present the review activity as support for individuals' personal development and a check on projects' progress and deliverables. Reviews are seen as important for the sake of employees, projects, and clients. Not discussed, but equally significant is the role of reviews to inspect and correct the efforts of individuals and project teams. Such systemic monitoring and personal control elicits conformity to standard practice and firm values, while keeping in check the potential for autonomous action by individuals or project teams.

\section{Change in Forms of Control: Mediating Production with Information Technology} SCC's senior managers decided about eight years ago that to maintain their profitability ratio and beat the competition they needed to increase productivity, hence decreasing the length of systems development, and reducing the number of consultants required on each project. They also wanted to improve what they term "leverage" by increasing the number of consultants per senior project manager (expanding span of control), and they wanted to diminish their dependence on the technical knowledge required for the multiple computer configurations operated by their clients. In the past, SCC had to ensure that consultants knew a range of programming languages, database

3 This is an interesting form of recussion in action: the methodology contains prescriptions and procedures for a quality assurance review, the objective of which is to ensure that the project is executed according to the methodology. 
management, teleprocessing, and operating systems to be sufficiently versatile to operate in many different technological environments. Such knowledge is highly technical, idiosyncratic, and quickly becomes obsolete as new computer products continually appear on the market.

SCC managers decided to use information technology to automate parts of the production process, thus hoping to get the desired improvements in control and productivity. The information technology they chose to develop and deploy was productivity tools. ${ }^{4}$ The task of constructing productivity tools was delegated to SCC's technical consultants, who constructed computer routines that encoded knowledge of systems development and procedures to facilitate consultants' interaction with the tools. In this they were helped by SCC's methodology, which specified in detail the rules for executing each systems development task, and hence served as a valuable blueprint from which to build the tools. The productivity tools, thus, came to embody the tenets and prescriptions of the SCC methodology. Today, the use of productivity tools within SCC is mandatory on all large projects, and tools are a major component in the training of all SCC recruits.

For SCC, tools allow "working in a factory mode," a strategy seen by management as essential for business success. A few senior managers noted:

The tools enforce the methodology. In our concept of a factory you don't have a choice whether to use [the methodology] or not. It shouldn't be an option if you need to deliver something. There should be no guesswork here, and--I don't want to say this--but there should be no creativity. It has to be a determinate process.

I will do anything I can to control the possibility that people do not get too creative. How can I be sure that the guts of the system--the programs--are protected from people with smart and individual ideas about how they would do things? I use tools which allow me to shield things from these people.

By building standards into tools we can control what people do and how they do it. We are no longer dependent on the knowledge in people's heads. So if people leave, we aren't sunk. Tools allow us to put knowledge into a structure and embed it in technology. The management risk of the turnover of skilled people is reduced by using tools.

The use of technology as a systemic form of control is evident here, driven by the same motivations that drove earlier industrial endeavors to embed structural control in technical systems: predictability, standardization, productivity, independence from skilled workers, and cost control.

Tools have also increased the span of personal control, as a senior manager explained:

Our tools have had a tremendous impact on our firm in terms of leverage. You must understand that the key element in professional service firms is leverage, [that is] the number of professional service employees per manager. In smaller consulting firms where they build highly customized systems, like [name of competitor], they have a low leverage, about four or five people per manager. In the past we thought we were doing well if we had eight people per manager. But now with tools, SCC is in the factory business, so we want to have as high a

${ }^{4}$ See Orlikowski [1988a] for a detailed description of the particular productivity tools developed by SCC. 
leverage as possible, up to fifty people per manager. The average right now is about twenty people per manager, but we can do much better.

The notion of "leverage" crops up frequently in the discourse of SCC--in its brochures and training materials, and in how its members talk about their practice. It suggests the instrumental way in which SCC perceives and treats its employees, as resources to be manipulated for the firm's financial advantage. This is somewhat at odds with the rhetoric of SCC's recruiting material:

Our people are the catalysts who bring together scope and structure and growth and training and culture and opportunity to create a unique career environment. ... [This] is where people make the difference. (emphasis in original)

This is also at odds with trends in the manufacturing industry, where much attention is being paid to simultaneously automating the factory floor and improving the autonomy, experimentation, involvement, task content, and working conditions of production workers [Dertouzos, Lester and Solow 1989; Piore and Sabel 1984]. At first glance, it is curious that SCC, which as a consulting firm is intimately involved with automating and redesigning work practices for clients, does not attempt to change its personnel and production policies around the deployment of information technology in its own core work processes. More careful scrutiny reveals, however, that "democratization" of the SCC workplace would be at odds with its established aims and norms: hierarchical authority, rhetoric of professionalism, disciplined work practices, aggressive schedules, "up or out" promotion, high turnover, and short-term focus on current engagements and profitability. As one senior manager succinctly put it, when asked about the long-term implications of consultants' technical knowledge being reduced by the use of tools:

There is concern in the data processing industry that people are losing their skills, that skills are becoming obsolete. But it is not for us to judge that. It is for us to take advantage of that.

\section{Change in Systemic Forms of Control: Production Knowledge}

After tools were deployed in the production process, consultants and managers' discretion over production work changed. Before the onset of tools, SCC's methodology could be used or not, interpreted in different ways, and adapted to different situations. Consultants who had worked on projects before productivity tools recalled that they had had some choice in what aspects of the methodology to use on a project. Now that the methodology was embedded in the productivity tools, individuals have much less discretion over how they conduct their work. Which production tasks are executed is now under the control of the tools, which facilitate task performance. The tools prohibit execution of tasks unless all the prerequisite work (defined in the methodology) meets the tools' completeness criteria. This ensures that production tasks are executed in the prescribed order, and that all relevant information is available before a task is attempted. The tools also monitor task performance with extensive cross-checks of design documentation, searches for inconsistencies and ambiguities, and prompt consultants when errors or omissions are detected. 
Senior consultants who had experienced production work before tools, commented that they now had significantly less latitude in their work. With tools, they argue, they cannot choose to do a task differently to the manner specified in the methodology, nor can they choose not to do the task at all. For junior consultants who have had no prior exposure to developing systems, tools are not interpreted as restricting autonomy for they are unaware of other ways of designing systems. For them, the SCC approach embodied in its methodology and tools is the only way to develop application systems. A manager noted:

The fact that tools are a success in SCC is because we bring in lots of new people who are fresh and open to new things. They don't know how to do systems development, so they don't have to unlearn anything. They just learn what we tell them, and do what we tell them. The use of tools is disciplined, so we can mandate stuff as they know no better.

Much of this technical control is obscured behind "user-friendly" designs. For example, the tools' interface with consultants creates an impression of choice in that one can select which task to perform from a number of options. That this list is prescribed, that the sequence of tasks is controlled, and that their task execution is being constrained, is not obvious to many of the consultants. This is unobtrusive control--control over the premises of decisions and actions--as postulated by March and Simon [1958] and Perrow [1986]. While this form of control is perceived by some consultants and not by others, its influence is generally effective. Embedding the methodology in the tools makes it less visible, hence less open to criticism, with the result that consultants do not question the appropriateness of certain of the methodology's rules, guidelines, and standards. A senior consultant commented:

The methodology was used to set up the tools, so the methodology is now hidden in the tools. By using the tool set we are reinforcing the methodology. But at the time of using the tools we aren't exactly aware of how the methodology underlies the tools. So we are hiding the methodology in the tools, and the use of tools forces our use of the methodology and promotes certain work habits without our awareness.

Consultants' focus in using the tools and methodology is consequently instrumental--geared towards getting the job done and "the product out the door"--matching management's concern with budgets and schedules. The facilitative and constraining aspects of information technology [Orlikowski 1991] are evident here. SCC's use of productivity tools enables productivity and predictability in the production process, while restricting the range of actions known or available to the workers. This duality is a central theme of Foucault's disciplinary power [1979:138]: "Discipline increases the forces of the body (in economic terms of utility) and diminishes these same forces (in political terms of obedience). ... [D]isciplinary coercion establishes in the body the constricting link between an increased aptitude and an increased domination." 
Because SCC hires almost exclusively at entry-level, and hires from a range of degree programs, it retains a great deal of control over the definition and nature of the knowledge needed to perform the production tasks. Productivity tools have changed the nature and level of knowledge required to execute certain tasks. Most people acknowledged that deskilling has occurred through the use of tools. In SCC, the distinction between deskilling tasks and deskilling workers ${ }^{5}$ is not apparent because individuals are always moving in SCC (up or out), and do not experience their tasks being redefined in terms of less knowledge content. One manager observed: "You must understand that in SCC tools do not deskill our people, rather they don't skill them, because the people didn't have the skills in the first place." The manager's point is accurate with respect to junior consultants. In SCC, new recruits enter the firm without consulting knowledge or experience. Before the production process was mediated by information technology a large part of a new recruit's training program was learning technical knowledge. Since the computer-mediation of production tasks, such technical training has been halted, new recruits now only learn to use the firm's tools, and have lost the opportunity to gain technical knowledge. Through this process, SCC secures the ability to engage workers in production who are less knowledgeable and experienced (hence cheaper) than those who previously occupied the same position in SCC's hierarchy and production process. A manager noted that the firm's methodology and tools were essential, because:

We're billing people after three months with SCC and throwing them into different environments, so we have to make sure that they are always productive, as we want to bill them out from day one on a project. We don't want to have to account for a leaming curve on each job.

Most senior managers admit that economic and productivity benefits generated by deskilling make it one of the main reasons for deploying tools. A few commented:

With tools we can make money leveraging people, that is, having many bodies even at lower rates can be profitable with tools. Tools allow us to do what we are always trying to do in SCC, to push work down to the lowest skill level possible. They allow a factory mode of operating.

The skills issue is another motivator for us to develop and use tools. It is expensive to educate people, particularly in the technical details. If we can embody the knowledge of technical experts in the tools, then a less experienced person can work with the tools and become an expert. So we factor out the complexities of systems development and embed these in the tools. Then we can forget about them because the tools insulate us from the technical environment.

We use tools to leverage people's skills. One person who is more skilled than everyone else does the program shells, and then you can take people who are less skilled and they can use those shells. So we don't reinvent the wheel. And instead of everyone having to get the same level of skills, we only need a few people with the higher skills.

\footnotetext{
5 The processes of deskilling affecting jobs are not synonymous with those affecting individuals. For example. while a particular task may be deskilled by being made simpler and more routine. the particular job incumbents may not be deskilled for they may now focus on the more skilled aspects of the job, with the deskilled lask being executed by a different set of workers [Attewe]] 1985; Lee 1981].
} 
Since the deployment of information technology, the tools have come to constitute an important component of the role-specific vocabulary transmitted to consultants during training. The use of productivity tools reinforces the ideational control evident earlier in the use of the methodology. While consultants clearly use the methodology and tools carefully and seriously, they also tend to take them for granted. Such uncritical appropriation of methodology and tools proves to be an effective control of consultants' assumptions, values, and actions. The methodology and tools are not only instrumentally important in coordinating the production process of SCC, they also mediate a shared reality within SCC, facilitating uniform behavior. This allows replacement of consultants on projects. A junior consultant noted that the methodology and tools allow "... the interchangeability of parts, that is, of humans." The methodology and tools help SCC's production process operate efficiently through standardization, while ensuring substitutability of consultants is an important hedge against project failure. A manager remarked:

The methodology and the training turn us all into clones. And of course, SCC wants us to be clone-able, because of the high tumover. So it can replace me if I leave tomorrow, else it can't turn out the service level it wants to.

\section{Change in Systemic Forms of Control: Impression Management}

Tools significantly enhance the "make-expert" tactic practiced by SCC. A senior manager said: "We have found that with tools the low-quality players are also able to contribute to the project," while a manager noted that tools allowed the firm to use novice consultants as if they were experts:

Productivity tools allow us to leverage inexperienced people on our project. So we can take a kid out of school, let's say with a major in English, and in a very short time he can achieve high productivity, that is, achieve the productivity level of a client programmer with ten years experience. It's not that we are making him more effective at his job, but we are dumping him into a production environment that has ten years of programming experience built into it.

This tactic has significant financial benefits for SCC, allowing, as a manager explained, increased profitability on projects:

The rule of thumb in professional consulting firms is to bill your professionals at three times their salary. But now with tools we can bill up to six times salary.

In addition to "make-expert," tools allow a another way of controlling conduct on projects. Returning to Goffman's distinctions of frontstage and backstage, an important requirement of SCC's frontstage is giving the impression that one is working hard at all times. Because SCC managers and consultants are situated in full view of the clients who are paying for their services, they continually manufacture the impression that they are working intensely. A manager observed:

Client management are always very anxious about how much they are paying us. They always think it is too much, so we have to show them that we're working very hard, all the time, so as to impress them. 
Productivity tools help significantly in these attempts at what I call "make-work" impression management. A senior manager commented:

Because we operate on the concept of leverage, we must make our young, inexperienced people who we charge lots of money for, appear to be very productive. And tools allow us to do that.

Tools render an image of a room of consultants seated in front of personal workstations, bent over keyboards, flashing through complicated-looking screens, performing sophisticated cut and paste procedures, and all done to the accompaniment of the reassuring whir of the disk drives, the steady tapping of keys, and the regular sigh of the laser printer emitting its professional-looking documentation. It certainly looks industrious. The tools appear to be very useful props in this front region, helping to manage meaning, conveying the impression of work and productivity, and creating the illusion, if not always the substance, of competence and effectiveness.

At a more general level, the use of information technology by SCC has significant connotations. It is a potent symbol of industrial progress. In the careful labeling and packaging of technology as productivity tools particular meanings and images are conveyed. A number of researchers [Boland 1987, 1989; Hochschild 1983; Lakoff and Johnson 1980; Turkle 1984] have detailed the powerful ways that the metaphors used in daily discourse, shape and sometimes obscure understanding of social processes. In the similar vein, I suggest that the use of metaphors to describe the information technology used in production work has a profound influence on how people experience that technology. That is, the portrayal of the information technology mediating SCC's production process as productivity tools generates a particular understanding of the technology. The notion of technology as tool highlights the facilitative and downplays the constraining aspects of the technology. SCC's way of talking about productivity tools suggests, unproblematically, that they are useful, independent, objective, instrumental, harmless, stable, appropriate, accurate, manipulable, neutral, as well as having known, predictable, universal effects and meanings. Such connotations get in the way of understanding the relationship between information technology and forms of control and organizing. In particular, they obscure the socially constructed essence of technology, its contextual nature, and unanticipated effects [Orlikowski 1988b, 1991].

\section{Change in Personal Forms of Control: Electronic Supervision}

The use of productivity tools on projects has significantly changed the relationship between delegating and monitoring work. Some commentators suggest that information technology encourages delegation of production tasks to lower-level workers, hence increasing their relative autonomy. While tools do facilitate increased delegation on SCC projects, paradoxically, they only do so because they simultaneously facilitate increased monitoring. A project manager explained:

As the project team grows bigger in size--say up to fifty people--you have to give people a 
measure of independence, as it is impossible for me to keep track of what everyone is doing. But tools allow me to keep my finger on the pulse of the project, and keep tabs on what's going on everywhere. Tools allow me to sample--via the management reporting system--various pieces of people's work. So I can zoom down onto problem areas, and zoom in on the details. This way I can monitor the quality and completeness of what's being entered into the tools. Tools give me an informal mechanism for getting a handle on what's being done on the project.

While tools appear to provide for increased decentralization in that there is more delegation of work, they also increase centralization through a capability to directly monitor work. Storey's [1987:55] study detected this same phenomenon in an insurance company which referred to it as "delegation with control." By mediating direct supervision electronically, tools on SCC projects expand the scope of personal control to include control over behavior as well as outcomes. Managers now have the capability to review not only work products, but also work in progress. To the extent that electronic monitoring becomes institutionalized within the tools, the personal control of direct supervision has been transformed into systemic control.

Electronic supervision invokes the Panopticon [Foucault 1979; Zuboff 1988], Bentham's social machine that in the eighteenth century provided automatic and continuous control through a physical architecture that afforded constant surveillance. Constant surveillance--whether physical or electronic--does more than just exert direct control over individuals. It entraps them in their own control because its effectiveness depends not on its actual exercise but on their belief that they are subject to it. As Foucault [1979:202] notes: "He who is subjected to a field of visibility, and who knows it, assumes responsibility for the constraints of power; ... he becomes the principle of his own subjection."

\section{Change in Client Relations}

While clients do have some input into whether tools are to be used on their projects, many consultants observed that, by and large, clients go along with what the consultants suggest. A manager remarked:

SCC has brainwashed us that all projects have to be tool-oriented. So we try and force them [tools] onto clients, and this can cause a rift between the client data processing people and us. But usually we can bully the client into using our tools. The senior manager forces the issue by saying the project will cost so many millions of dollars more if they don't use the tools.

Client involvement on SCC projects is mandated by firm policy, although, there is far more ambiguity about the role of clients than would be suggested by merely counting client team members. Despite the considerable presence of client personnel on SCC projects, the degree and level of client involvement appears to be relatively limited. Client personnel are required to use SCC's methodology and tools, and are directed in their work by consultants who make most of the design and technical decisions. Thus, they have to master a new perspective and a new way of 
building systems, which often conflicts with their more traditional assumptions and experiences. As a consequence, client involvement is passive and often appears more symbolic than substantive.

Tools have also influenced consultants' interaction with clients. A senior manager reported:

The disadvantage of productivity tools at the design stage is that they focus on the design details, instead of the business problems. In the past we would focus more on what is required, now we tend to fill our design documentation up with how, all the details of screens and reports. And the clients get blown away by the technical design documentation because it is so flashy, and it looks so right.

SCC's methodology and tools come equipped with a set of concepts and rules which are used by consultants to understand and model organizational realities which they then automate. The methodology defines techniques for collecting user requirements, specifying the format of interview, nature of questions and method of data representation. In the projects that I studied, SCC's methodology specified a "checklist" of questions that consultants used to interview users, prompting the elicitation of certain work experiences and information uses. The questions were structured to evoke responses that could be represented in the tools. Here, SCC's methodology and tools sensitized the consultants to ask specific, directed questions, focused their attention on certain--operational--aspects of users' reality, ignoring many social, political, and informal arenas of organizational life that were not expressible in the medium of the methodology or tools.

The formalization of work practice implicit in the tools encourages consultants to take things at face value and to follow routines. Routinization reinforces SCC's results-orientation, as Hall [1982:101] notes "In organizations that establish highly specific routines for the members to follow, there is likely to be little time, support, or reward for involvement in new ideas and new programs." The standardized responses promoted by tools induce a passivity among consultants which discourages "reflection-in-action," Schön's [1983] term for participative engagement of practitioners with their situation. Such reflection requires the surfacing and criticizing of taken-forgranted understandings, constructing different interpretations, and experimenting with new techniques. In contrast, practitioners that are inattentive to their practice context breed "a parochial narrowness of vision" and where behavior becomes more repetitive and routine, "the practitioner may miss important opportunities to think about what he is doing ... and afflict his clients with the consequences of his narrowness and rigidity" [Schön 1983:60-61].

\section{Dialectic of Control}

Despite the apparent determinism of the control mechanisms I have outlined above, some consultants are able to distance themselves from them. Through humor, irony, and detachment, these consultants penetrate the forms of control structuring their workplace. Occasionally, they 
even take action that undermines the workings of these control mechanisms. A few illustrations around productivity tools are available.

When consultants believe the technology is slowing their work they may deliberately bypass the tools. Such a tactic can only be employed by consultants who have sufficient technical skills to know how to circumvent the tools, and who know how to continue working without the support of the technology. A senior consultant explained:

The tools try to do too much. For example the tools check referential integrity of all your data which is a great way to enforce the integrity of people's work. But sometimes when you're just testing something you don't want everything to be thrown out just because you're violating integrity. You're still developing, so things are not going to be perfect. So if we find the tools too constricting or inefficient we go around them.

When asked if this did not undermine the operation of the tools, he replied:

Yes, of course, and we get kicked for doing it from two sources: from the managers as they really get mad when they find out, and from the tools because there are ramifications for not doing something in the tools. You find you can't do other things in the tools, and then you may have to do rework. So it is not really worth it in the long run. But the problem is that often we are rushing to get something done, and the pressure is on, and so we just think short term.

Another example involves the lack of technical learning that some consultants believe they are experiencing because of the tools. On one large project the consultants and client system developers on the team complained that the tools were screening them from interacting with the new database system that was being used on the project. They felt cheated of the opportunity to learn the new software product and acquire new technical skills because the tools prevented their accessing it. Eventually, to appease the mounting dissent, the project and client management agreed to let the team members be trained on the new database product, at the expense of the project's budgets and schedules. A senior consultant noted:

So we started having regular training sessions which were quite unrelated to the project. That is, we were giving people skills they did not need. This is a huge commitment for management, about two hours a week for thirty people.

While such action against the controls of the tools does occur, it is not common. When it does occur the consultants are typically reprimanded, accused of not being "team players," often getting negative reviews. Nevertheless, it is important in this discussion to underscore that the exercise of control is never one-sided. SCC consultants, on occasion, are able to refuse to conform to the tools and the culture, and do things the way they see fit, reaffirming their knowledgeable agency. As agents, consultants appropriate knowledge expeditiously, and sometimes challenge institutionalized practices [Freidson 1986:215]. 
A more common, and more final, expression of the dialectic of control is exiting. SCC's turnover rate is extremely high, even for consulting firms. Accurate figures for turnover in SCC were not available, but speculations ranged from 25 to 40 percent. ${ }^{6}$ Employees suggest that the conditions of the job may be a factor in this high rate of turnover. A manager noted:

Now that we are growing so much we are losing really good people, because they just get lost in the crowd. We lose our best people because we run this place like a bodyshop and treat people as fully replaceable, which I suppose in our work, they are. ... The biggest problem with SCC from the point of view of the personnel is that it is a very dehumanizing firm. We are all just drones here.

One senior consultant noted that:

Everyone in SCC with less than four years is just like fodder. SCC uses these people as cheap labor and treats them that way.

Such sentiments are likely to encourage some resentment to control that is considered unreasonable, and as indicated, some of this does get expressed. By and large though, it seems the dialectic of control is not expressed because of SCC's ability to manufacture consent [Burawoy' 1979] among its consultants who accept the control imposed on them. SCC's culture, its focus on individualistic career stages, and its ideology of professionalism are all relevant in engendering this consent, and in ensuring the use of the methodology and tools in project work. Use of the methodology and tools, in turn, reinforce the culture and consent by demanding "professional" conduct, hard work, and adherence to SCC's norms and practices.

\section{DISCUSSION}

The above has described a number of key control mechanisms in effect within SCC before the deployment of information technology, and examined the influence of information technology on these control mechanisms. The results indicate that, contrary to certain expectations in the literature, information technology is not necessarily associated with flexible or de-bureaucratized forms of organizing. Instead, we see the emergence of technical control, and the augmentation of personal, social structural, and cultural control through electronic mediation. A review of SCC's stated objectives behind the decision to deploy information technology indicates that these resuits are largely consistent with the objectives. SCC management wanted productivity tools to reduce projects' need for managers and technical skills, to improve the efficiency and productivity of projects, and to increase the substitutability of consultants. There was no explicit intention to restructure the organization, to decrease the level of hierarchy, or to empower lower-level employees. These results--albeit from only one organization--highlight, yet again, the fallacy of technological determinism. Technologies are built to meet certain objectives at a particular point in

\footnotetext{
${ }^{6}$ Adler [1987:12] reports that the overall tumover of staff in management consulting firms varies from 18 to 28 percent.
} 
time. The productivity tools' particular form and functioning reflect the tool developers' interpretations of SCC's management strategic intentions in the early eighties. Within SCC, the information technology was introduced into the production process to augment and automate established work practices. Because the technology was built to reflect the existing organizational order, its use on project teams now serves to reinforce rather than transform the status quo.

\section{Implications for Forms of Control}

The SCC results, however, do indicate how information technology can influence the control mechanisms employed by an organization. Before the deployment of productivity tools, production tasks and norms within SCC were informed by the rules embedded within SCC's methodology. However, as Giddens [1979:148] points out, "rules do not follow or interpret themselves," and the rules of the methodology had to be appropriated by SCC workers to have effect. In this appropriation, the production rules were not followed unilaterally, being subject to the application, negotiating, and circumvention that typically befalls written rules. While informing workers' execution of production tasks, the rules were not embodied within the medium through which the production activity was to be accomplished. There existed a conceptual and physical distinction between the written rules of the methodology and the action taken by workers. Thus, consultants and managers had some latitude in interpreting and applying the production rules, and even violation of rules was tolerated provided that the outcomes met SCC's quality criteria.

In deploying information technology in the production process, SCC embedded the rules of the methodology within the productivity tools. In this move, the rules defining production tasks became embodied within the medium through which the production activity is accomplished. There is no longer a conceptual and physical distinction between the production rules and the action taken by workers. Here, SCC managers and consultants cannot effectively engage in production activity without utilizing the productivity tools and hence without invoking the rules. In this fusion of rules and means of production, consultants and managers lose some discretion in interpreting and applying the production rules. The effect is particularly accentuated within SCC, because of senior managers' desire to formalize, standardize, and protect the core work processes as they grow their business. Ignoring, modifying, or circumventing production rules is problematic now as it requires ignoring, modifying, or circumventing the productivity tools. Breaching production rules under such conditions is much more difficult than before tools were introduced, because such action is more visible, requires technical skills, is not sanctioned, and has significant direct effects on other production tasks now integrated through the technology.

An important outcome thus, of using information technology to mediate production work, is the 
embedding of production rules in the means of production. This resembles technical control as exercised through the structure of mechanized production lines, but escalates it through the symbolic nature of information technology. Where technical control has tended to be associated primarily with physical effort, information technology extends its effects into the sphere of mental effort. By influencing cognitivin, iechnical control mechanisms become closely aligned with mechanisms of ideational control which shape the assumptions and mental models that workers draw on to understand and accomplish their work. These forms of control thus both enable and constrain worker action in the production process.

Similarly, the technical control embodied in information technology becomes coupled with personal control in that the direct supervision indicative of personal control can now be expressed as electronic supervision through the information technology. By mediating and augmenting direct supervision through electronic surveillance, information technology extends the scope of control in time and space as workers can be distributed over different locations and can work different time shifts and still be coordinated through the technology. It also extends the scope of control in terms of reach in that managers can unobtrusively examine employees' work in progress by monitoring their electronic workspaces, workfiles, and computer usage data. A requirement of managers' increased monitoring capability is that they be literate in the use of technology and be able to comprehend and manipulate the data collected on subordinates' performance [Cohen 19\& $7: 166$ ]. They now need to get more involved in the details of work as it is mediated by information technology. Managers' actions are thus also dependent on the technology. As Foucault [1979:204] notes, the supervisor's own fate is bound up with the mechanism he uses to discipline others.

To the extent that the internal forms of control--cultural, personal, social structural, and technical-become more integrated through being embedded in information technology, we may be seeing the emergence of a new control mechanism, which fuses a number of previously separate mechanisms. Storey [1985:206] suggests that with the increased deployment of information technology in production processes, a new integrated, computer-based control mechanism may develop. I suggest that the findings from SCC lend early, empirical support to this proposition. The mediation of work processes by information technology creates an information environment which appears to have contradictory implications for forms of organizing and control. The information environment, while it may facilitate integrated and flexible operations, may also enable a disciplinary matrix of knowledge and power. The former resembles the "informate" concept, coined by Zuboff [1988:9] to express the ability of information technology to generate "information about the underlying productive and administrative processes through which an organization accomplishes its work." Zuboff suggests that this "informating" ability of information 
technology allows managers to transform organizations into "learning institutions," noting [1988:311] "An emphasis on the informating capacity of intelligent technology can provide a point of origin for new conceptions of work and power." Zuboff, however, does not acknowledge that technology's "informating" capacity can just as easily be used to increase systemic forms of control in organizations. ${ }^{7}$ There is nothing inherent in technology's informating potential that ensures a transformation in the workplace. Zuboff [1988:9] observes that: "Information technology not only produces action but also produces a voice that symbolically renders events, objects, and processes so that they become visible, knowable, and shareable in a new way." Such transparency is at the core of disciplinary power [Foucault 1979], and from this perspective the information environment can be seen as a matrix of control, fusing together a range of capabilities that facilitate a repressive and more embedded means of control. As Boland [1989:281] notes: "The forms of knowing expanded by information systems are forms of power."

The experiences of SCC illustrate how extensively information technology is implicated in the structuring of actors' daily activities through their use of the tools, providing rules and resources to accomplish work, assign meanings to events, objects, and relationships, and coordinate action over time and space. In this light, Giddens' [1985] treatment of technology as only an allocative resource needs to be clarified so that the influence of technology as an authoritative resource-organizing social time-space, shaping social interaction, and constituting actors' organizational life chances--can be recognized and analyzed. The extent to which information technology facilitates a fusion of control mechanisms reveals how significantly it intermingles the social and technological domains, accomplishing not only technical but also social rationalization [Heydebrand 1989]. In this, information technology appears to resemble what Giddens [1979:74] refers to as systems technology, “... the incorporation of human beings, or their activities, within designed control systems." This interpenetration of the social with the technical realm challenges the unproblematic distinction between them sustained by socio-technical systems analysis. The social and technological domains are inherently intertwined, and the fusion accomplished by information technology makes their disconnection even more untenable.

\section{Implications for Forms of Organizing}

Embedding production rules within the medium through which work is done has a number of structural implications. The active application of the methodology's rules to production tasks has been replaced with a passive use of the rules as they mediate the execution of production tasks through the tools. While facilitating practical action, use of the tools constrains reflection. By being

\footnotetext{
7 as in fact many of her case studies illustrate [Zuboff 1988].
} 
embedded in technology the production rules become reified and taken for granted, diminishing the potential for workers to reflect on their action. They encourage implicit acceptance of procedures and routines as "fixed," and as "circumstances they are unable to change" [Cohen 1989:194]. It also suggests that the production tasks and norms being defined by the rules will be harder to change as they are no longer separate from the technology, and hence are difficult to distinguish and reflect on. Further, modification of rules embedded in computer code requires technical expertise and authority. Before the deployment of information technology, change or reinterpretation of written rules was more easily accomplished by the workers.

To the extent that control mechanisms have become fused through information technology, use of the technology now not only facilitates and constrains action, it also reinforces the production process of SCC and its control mechanisms, reproducing over time the firm's existing structures of authority, knowledge, and legitimacy [Giddens 1984; Orlikowski 1991]. The integration of information technology and forms of control also has a number of contradictory implications. In SCC, the productivity tools embody technical knowledge and administrative authority, and improve the efficiency and productivity of the production process. They appear, on the surface to be effective technologies, enabling SCC to implement its production strategy, and enabling SCC workers to more efficiently accomplish their production work. Yet, because the information technology is also a form of control over production, it mediates the production process, and individual workers and project teams have become increasingly dependent on it. There is an interesting irony in SCC's use of information technology, in that even as they use it to sell and deliver technological "solutions" to their clients, promising to transform clients' work practices and forms of organizing, their use of information technology has not transformed their own work practices.

SCC's production process is physically dependent on the information technology in that the entire production process is disrupted if the tools are in error or out of order. The disruption is aggravated because the information technology has integrated the various tasks constituting the production process. Production tasks are now intertwined with each other and linked to the tools so that any breakdown in the tools disrupts the performance of all the tasks. Such interactively complex and tightly coupled systems while highly powerful, are also vulnerable because they are prone to multiple and unexpected interactions of failures-."normal accidents" [Perrow 1984]. The fusion of production tasks to information technology may also organizational complexity, which as Heydebrand [1989:350] points out, may generate "endogenous sources of uncertainty and instability" which may contribute to the very conditions the technology is attempting to alleviate. Another form of dependence concerns the timeliness and relevance of the "knowledge" embedded 
in technology. SCC's productivity tools embody the assumptions, rules, and concepts of a methodology that was developed in the seventies. The appropriateness of this knowledge over time represents a significant dependence for SCC. If a radical change in software development knowledge should occur, much of the methodology and productivity tools would need to be changed significantly.

SCC's workers, particularly the more junior consultants who have had no prior experience with systems development, become dependent--through training, socialization, and experience--on the productivity tools. Such actors lose the ability to reflect on the assumptions, rules, and concepts that facilitate and constrain their work. They lack conceptions of "how things could be otherwise" [Giddens 1979:149]. Without a capability to question and modify schemas and behavior, such workers are unlikely--without significant reorientation and retraining--to be adaptable or effective in different production circumstances, particularly future systems development environments which may be premised on quite different assumptions about systems and technology.

The dependence of consultants and the production process on the information technology may mean that the short-term gain in productivity and competitiveness afforded by the productivity tools could lead to SCC's long-term incapacity to respond flexibly to dynamic business conditions. Technology that mediates the production process of an organization is critical to the ongoing operations of the firm and hence strategic. A strategic technology, while it may be part of an organization's competitive initiative [Ives and Learmonth 1984; McFarlan 1984], may also be its key vulnerability. Two contradictions inherent in SCC's productivity tools arise as a consequence of this interdependency. First, the flexibility promised by productivity tools and implied in its surface labeling is undermined in practice because of the way the technology was designed and implemented. Within SCC, the productivity tools are not tools so much as the embodiment of human knowledge and skills, employed to increase uniformity and control, and decrease dependence on professional workers. Deskilling, apparent in blue collar work [Braverman 1974; Shaiken 1984], takes a different form in consulting work--not skilling workers at all. This ability to rely on the knowledge embedded in technology rather than on that held by workers further weakens SCC's claims to being a "professional" firm. Not only is there a complete absence of professional control mechanisms in effect at SCC, either before or after use of technology, but the very use of information technology appears contradictory to SCC's well-articulated ideology of professionalism.

The second contradiction arises because of the coupling of tasks to tools and the dependence of consultants on tools. Under such conditions, the arena for worker action is paradoxically increased 
even as management has increased control. In the interdependence of development tasks and the centralization of production control via the tools, SCC's production process has become more susceptible to disruption by strategically placed workers and managers. If consultants choose to develop their own tools or choose to neglect the sanctioned tools, SCC's control mechanisms lose their effect. Thus, while the autonomy of consultants may have been limited by productivity tools in some areas, in other respects they have gained power, as they have a key arena within which to express their disaffection. As we saw above, in SCC this is not a significant concern. In other organizations, or within SCC under other circumstances, it may be.

The role of human agents in enacting the forms of control to which they are subject is central. It is through drawing on the tools to accomplish their work that consultants reinforce the centralizing and controlling tendency of the tools. Through the socialization and training of consultants into the methodology and tools these aspects of the production process become part of the culture of SCC. Their use is thus reinforced through the consultants' participation in SCC's culture, even as the use of methodology and tools in turn supports SCC's culture, reaffirming its homogenizing philosophy by encouraging consultants to think and act predictably, and in ways that support SCC's production process.

This tendency for control and reification evident in SCC's culture and technology, however, should not lead us to discount the potential of human agency. For while managers can embed production rules, concepts and assumptions in technology, which will structure workers' cognitions and performance of production tasks, such control is never deterministic. It is contingent on the workers' acceptance of the legitimacy of the managers and the validity of the information technology. Such control can always be negated by the workers' refusal to accept the technology and its embedded rules as appropriate. Workers socially construct the technology they use, imposing their own meanings on the technology by appropriating it in various ways, modifying its built-in routines, and adjusting their procedures around its use [Orlikowski 1991]. As we saw above, SCC consultants engage with their workplace through various degrees of ideological commitment, cynicism, detachment, and--infrequently--with direct action that undermines the production rules. Through such agency, consultants invoke the dialectic of control to assert themselves, albeit at some risk to their stature and tenure in the firm. Cultural control, as Elster [1983:85] reminds us, while shaping desires and preferences, does not deprive individuals of all aspects of choice. It is a process that influences values which may lead to cerain action in given situations, but it does not directly determine action without individual mediation. Likewise, Dermer and Lucas [1986] note that control systems never effect unilateral exercise of power, they can at best proscribe, rather than fully prescribe workers' behavior. Thus, while we may posit that 
existing forms of control and organizing tend to be expanded and fused as information technology is deployed in production, this tendency must be qualified by recognizing that humans as selfconscious and capable agents always mediate the realization of that control, and hence can--and under certain conditions will--act to change it.

\section{Implications for Consulting and Professional Practice}

Some of the findings discussed here may also have implications for related organizations whose practices and policies resemble those of SCC. In particular, management consulting organizations and management advisory divisions of accounting firms have similar work processes, and many are contemplating or implementing information technology investments. As a consequence, we may see similar changes in control forms and work practices occasioned by the use of information technology. The implications for accounting firms are especially interesting. Accounting firms, as professional firms, typically adhere to a strong code of ethics which espouses among other things, service for the public welfare. For example, the ethical code of the American Institute of CPAs explicitly recognizes that: "A distinguishing mark of a professional is his [sic] acceptance of responsibility to the public," and that the professional is responsible to client needs only insofar as those needs are "... consistent with his [sic] responsibilities to the public." 8 The American Association for Computing Machinery likewise requires its members to "... consider the health, privacy, and general welfare of the public" in the performance of their work. ${ }^{9}$ SCC, in its 1985 annual report described itself as consisting of: "... dedicated business professionals with the analytical skills, personal integrity and objectivity needed to serve clients and the public interest." The "objectivity," "integrity," and "independence" inherent in a public service stance would appear to be undermined by the short-term focus on profits evident in SCC and its emphasis on standards, routines, methodologies, and tools that shape the reality they purport to serve.

Further, professional firms are granted the right of self-regulation and hence are intended to support professional autonomy. This is weakened by the embedding of production rules in the means of production, and the fusion of controls implicated in information technology. In SCC, we saw how the autonomy and self-regulation of individual practitioners is undermined by the focus on leverage, substitutability of individuals, and enforcement of disciplined work practices. While methodologies and tools may afford consultants some technical autonomy vis-á-vis their clients, those same methodologies and tools limit their professional autonomy not only to better serve client needs, but also to serve the public good. At SCC, it appears that the "professional" workers

\footnotetext{
8 American Institute of Certified Public Accountant Code of Professional Ethics, section 51.01.

9 Association for Computing Machinery Code of Professional Conduct, section EC 5.1.
} 
become less competent as knowledgeable agents as they become less able to reflect on their means of production and the knowledge embedded therein. Thus, to the extent that information technology is being used in accounting firms to transform the practices of management consulting-and possibly even auditing and tax--these firms may themselves be transformed by a fusion of controls, standardized client relations, inflexible technological imperatives, internal conflicts over professional authority and autonomy, and contradictions in objectives--their own, those of their clients, and those of the public good.

\section{CONCLUSION}

The results reported here--while bounded by their scope--strike a cautionary note in the midst of the optimism surrounding the new electronic organization. While provocative, the speculations about technology transforming the workplace do not deal with a number of important organizational issues--that are significant in any movement towards a computer-mediated workplace--traces of which we have seen in the results described here. Most of the current discussions downplay the tremendous difficulties associated with successfully implementing organizational change. Organizations typically display inertia through their established routines, institutionalized practices, and taken-for-granted assumptions that inform and reinforce the status quo [Hedberg, Nystrom and Starbuck 1977]. Reorientatin ; and restructuring (or in new wave parlance, "re-engineering" [Hammer 1990]) production processes under such conditions is not only difficult but also risky [Hinings and Greenwood 1988]. Speculation about technological transformations of organizations, by and large, ignore the motivations and interests of managers who will need to be instrumental in enacting such a changed world. Managers not only have vested interests in an existing order, they also tend to be rooted firmly in a given understanding of reality, making acceptance of an alternative structural order and new view of the world problematic [Schein 1987; Starbuck 1988; Storey 1987]. Finally, these speculations disregard inherent characteristics of information technology's design and use in organizations: that there are essential difficulties in developing complex, reliable, and appropriate information technology [Brooks 1987; Perrow 1983], that information technology tends to be designed to reflect the organizational status quo, and that the use of information technology encourages its institutionalization and reification [Orlikowski 1991].

This paper has described a study which examined the extent to which implementation of information technology in production is associated with changes in forms of control and organizing. The results indicate that no new organizational forms emerged, while the existing forms of control were intensified and fused, albeit with some contradictory implications for the long-term viability of the firm. We see the emergence of an integrated information environment as 
well as a matrix of control. This study highlights the tendency of managers and system developers to implement information technology which embodies existing forms of knowledge, legitimacy, and authority, and hence their tendency to support the status quo. It explicates the more subtle and unoburusive forms of control that emerge when production rules become embodied in the very medium in which workers conduct their activities. Finally, it reaffirms the notion of control as a dialectical relationship, as enacted and potentially changed by individuals, and as sustained and reinforced through institutionalized mechanisms of internal and external control.

\section{ACKNOWLEDGEMENTS}

I would like to thank Dick Boland and Ted O'Leary for their constructive comments on earlier drafts of this paper.

\section{REFERENCES}

Adler, Paul S. "Skill Formation in U.S. Accounting Firms: Pressures, Trends and Options." Office: Technology and People, 3: 1987; 3-16.

Agar, Michael H. The Professional Stranger New York: Academic Press, 1980.

Speaking of Ethnography Beverly Hills: Sage Publications, 1986.

Aldrich, H. and Mueller, S. "The Evolution of Organizational Forms: Technology, Coordination, and Control." Research in Organizational Behavior, Geenwich CT: JAI Press; 1982; 33-87.

Applegate, Lynda M., Cash, James I. Jr. and Mills, D. Quinn "Information Technology and Tomorrow's Manager," Harvard Business Review, November-December 1988: 128-136.

Attewell, Paul "The De-Skilling Controversy." Working Paper, Sociology Department, State University of New York, Stony Brook NY, 1985.

Barley, Stephen "Technology as an Occasion for Structuring: Evidence from Observation of CT Scanners and the Social Order of Radiology Departments." Administrative Science Quarterly, 31: 1986: 78-108.

Berger, P. and Luckmann, T. The Social Construction of Reality New York, NY: Anchor, 1967.

Birnberg, Jacob G. and Snodgrass, Coral "Culture and Control: A Field Study," Accounting, Organizations and Society, 13:5; 1988: 447-464.

Boland, Richard J. "Control, Causality and Information Systems Requirements." Accounting, Organizations and Society, 4: 4, 1979; 259-272.

"Discussion of 'Accounting and the Construction of the Governable Person,"' Accounting, Organizations and Society, 12: 3, 1987; 267-272.

"Metaphorical Traps in Developing Information Systems for Human Progress," in Klein, H.K. and Kumar, K. (eds.) Systems Development for Human Progress, New York: NorthHolland, 1989; 277-290. 
Braverman, Harry Labor and Monopoly Capital: The Degradation of Work in the Twentieth Century New York: Monthly Review Press, 1974.

Brewster, C.J. "A Typology of Management Controls," Procs. of the Fourth Annual Conference on Organizations and Control of the Labour Process, Aston UK, 1986.

Brooks, Fred P. "No Silver Bullet: Essence and Accidents of Software Engineering" IEEE Computer, April 1987:

Burawoy, Michael Manufacturing Consent Chicago: University of Chicago Press, 1979.

The Politics of Production: Factory Regimes Under Capitalism and Socialism London: Verso, 1985.

Child, John "Managerial Strategies, New Technology and the Labour Process," in Knights, D., Willmott, H. and Collinson, D. (eds.) Job Redesign: Critical Perspectives on the Labour Process, Hants, England: Gower, 1985; 107-141.

Cohen, Ira J. Structuration Theory: Anthony Giddens and the Constitution of Social Life New York: St. Martin's Press, 1989.

Czarniawska-Joerges, B. "Dynamics of Organizational Control: The Case of Berol Kemi AB," Accounting, Organizations and Society, 13: 4, 1988; 415-430.

DeMarco, Tom Structured Systems Analysis and Specification Englewood Cliffs NJ: Prentice Hall, 1979.

Dermer, J. D. and Lucas, R. G. "The Illusion of Managerial Control." Accounting, Organizations and Society, 11: 6, 1986; 471-482.

Dertouzos, M.L., Lester, R.K., and Solow, R.M. Made in America Cambridge, MA: The MIT Press; 1989.

Drucker, P. F. "The Coming of the New Organization." Harvard Business Review, JanuaryFebruary 1988; 45-53.

Edwards, Richard Contested Terrain: The Transformation of the Workplace in the Twentieth Century New York: Basic Books, 1979.

Elster, Jon Explaining Technical Change Cambridge UK: Cambridge University Press, 1983.

Feldman, S. "Management in Context: An Essay on the Relevance of Culture to the Understanding of Organizational Change." Journal of Management Studies, 23: 6, November 1986; 587-607.

Freidson, Eliot Professional Powers: A Study of the Institutionalization of Formal Knowledge Chicago IL: University of Chicago Press, 1986.

Foucault, Michel Discipline and Punish New York NY: Vintage Books, 1979.

Geertz, Clifford The Interpretation of Cultures New York, NY: Basic Books, 1973.

Giddens, Anthony Central Problems in Social Theory: Action, Structure and Contradiction in Social Analysis Berkeley CA: University of California Press, 1979. 
Profiles and Critiques in Social Theory Berkeley CA: University of California Press, 1982.

The Constitution of Society: Outline of the Theory of Structure Berkeley CA: University of Califomia Press, 1984.

Goffman, Erving The Presentation of Self in Everday Life New York: Doubleday, 1959.

Hall, Richard H. Organizations: Structure and Process Englewood Cliffs NJ: Prentice-Hall, 1982.

Hammer, M. “Reengineering Work: Don't Automate, Obliterate" Harvard Business Review, 1990.

Hedberg B., Nystrom P. C. and Starbuck W. H. "Designing Organizations To Match Tomorrow." TIMS Studies in the Management Sciences, 5: 1977; 171-181.

Heydebrand, Wolf V. "Technarchy and Neo-Corporatism: Toward a Theory of Organizational Change under Advanced Capitalism and Early State Socialism." Current Perspectives in Social Theory, 6: 1985; 71-128.

_ "New Organizational Forms," Work and Occupations, 16:3; 1989; 323-357.

Hinings, C.R. and Greenwood, R. The Dynamics of Strategic Change Oxford UK: Basil Blackwell, 1988.

Hirschhom, Larry Beyond Mechanization: Work and Technology in a Postindustrial Age Cambridge MA: MIT Press, 1984.

Hochschild, Arlie R. The Managed Heart: Commercialization of Human Feeling Berkeley CA: University of California Press, 1983.

Huber, George P. "The Nature and Design of Post-Industrial Organizations." Management Science, 30: 8, 1984: 928-951.

Ives, Blake and Learmonth, Gerard P. "The Information System as a Competitive Weapon," Communications of the ACM, 27:12,1984: 1193-1201.

Knights, David and Willmott, Hugh C. "Organizational Culture as Management Strategy: A Critique and Illustration from the Financial Services Industry," International Studies of Management and Organization,XVII:3, 1987: 40-63.

Lakoff, G. and Johnson, M. Metaphors We Live By Chicago: University of Chicago Press, 1980.

Lee, D. J. "Skill, Craft and Class: A Theoretical Critique and a Critical Case,"Sociology, February 1981; 56-78.

Leiffer, Richard and McDonough, Edward F. "Computerization as a Predominant Technology Effecting [sic] Work Unit Structure." in Procs. of the Sixth International Conference on Information Systems, Indianapolis IN, December 1985; 238-248.

March, James and Simon, Herbert Organizations New York: John Wiley and Sons, 1958.

Marx, Karl Capital: A Critique of Political Economy, Volume I, New York: Vintage Books edition, Random House, 1977. 
McDonough, E. and Leifer, R. "Effective Control of New Product Projects: The Interaction of Organization Culture and Project Leadership,"Journal of Product Innovation and Management, 3: $1986 ; 149-157$.

McFarlan, Warren F. "Information Technology changes the way you compete" Harvard Business Review, 1984.

Miller, Peter and O'Leary, Ted "Accounting and the Construction of the Governable Person," Accounting, Organizations and Society, 12: 3, 1987; 235-265.

Mintzberg, Henry The Structuring of Organizations Englewood Cliffs NJ: Prentice-Hall, 1979.

Noble, David F. America by Design: Science, Technology, and the Rise of Corporate Capitalism New York: Alfred A. Knopf, 1977.

Forces of Production: A Social History of Industrial Automation New York: Oxford University Press, 1986.

Ollman, Bertell Alienation New York: Cambridge University Press, 1976.

Orlikowski, Wanda J. "Information Technology and Post-Industrial Organizations: An Examination of the Computer-Mediation of Production Work," Unpublished Ph.D. Thesis, New York: Stern School of Business, New York University, 1988a.

"Computer Technology in Organizations: Some Critical Notes," in Knights, D. and Willmott, H. (eds.) New Technology and the Labour Process, London: Macmillan, 1988b: 20-49.

"The Duality of Technology: Re hinking the Concept of Technology in Organizations," forthcoming in Organization Science, 1991.

Orlikowski, Wanda J. and Baroudi, Jack J. "The Information Systems Profession: Myth or Reality?" Office: Technology and People, 4, 1989: 13-30.

Ouchi, W.G. "A Conceptual Foundation for the Design of Organizational Control Mechanisms." Management Science, 25: 1979; 833-848.

Ouchi, W.G. and Johnson, J.B. "Types of Organizational Control and their Relationship to Emotional Well Being." Administrative Science Quarterly, 23: 1978; 293-317.

Pennings, J.M. and Woiceshynm, J. "A Typology of Organizational Control and its Metaphors," Research in the Sociology of Organizations, Geenwich CT: JAI Press; 1987, 73-104.

Perrow, Charles "The Organizational Context of Human Factors Engineering." Administrative Science Quarterly, 28: 1983, 521-541.

Normal Accidents: Living with High-Risk Technologies, New York: Basic Books, 1984. Complex Organizations: A Critical Essay (3rd ed.) New York: Random House, 1986.

Piore, M.J. and Sabel, C.F. The Second Industrial Divide New York: Basic Books, 1984. 
Rosen, Michael and Baroudi, Jack. "Computer-Based Technology and the Emergence of New Forms of Managerial Control." Procs. of the Fifih Annual Conference on Organizations and Control of the Labour Process, Manchester UK, May 1987.

Schein, Edgar H. Organizational Culture and Leadership San Francisco CA: Jossey-Bass, 1987.

Schön, Donald A. The Reflective Practitioner New York NY: Basic Books, 1983.

Shaiken, Harley Work Transformed: Automation and Labor in the Computer Age New York: Holt, Rinehart \& Winston, 1984.

Starbuck, William H. "Why Organizations Run into Crises ... and Sometimes Survive Them," in Laudon, K. and Turner, J. eds. Information Technology and Management Strategy Englewood Cliffs NJ: Prentice Hall, 1989: 11-33.

Storey, John "The Means of Management Control." Sociology, 19: 2, 1985; 193-211.

"The Management of New Office Techriology: Choice, Control and Social Structure in the Insurance Industry," Journal of Management Studies, 24:1; 1987: 43-62.

Toffler, Alvin The Third Wave New York: Bantam Books, 1980.

Van Maanen, John "The Fact of Fiction in Organizational Ethnography" Administrative Science Quarterly, 24: 1979, pp. 539-550.

Tales from the Field Chicago: University of Chicago Press, 1988.

Wallace, Michael "Brave New Workplace: Technology and Work in the New Economy," Work and Occupations, 16:4; 1989; 363-392.

Yourdon, E. and Constantine, L. L. Structured Design New York: Yourdon Press, 1978.

Zuboff, Shoshana In the Age of the Smart Machine New York: Basic Books, 1988. 
$2935 \quad 60$ 
39080 0085625? 8

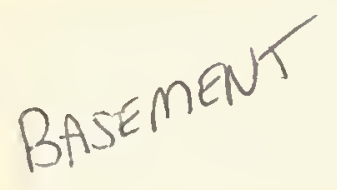





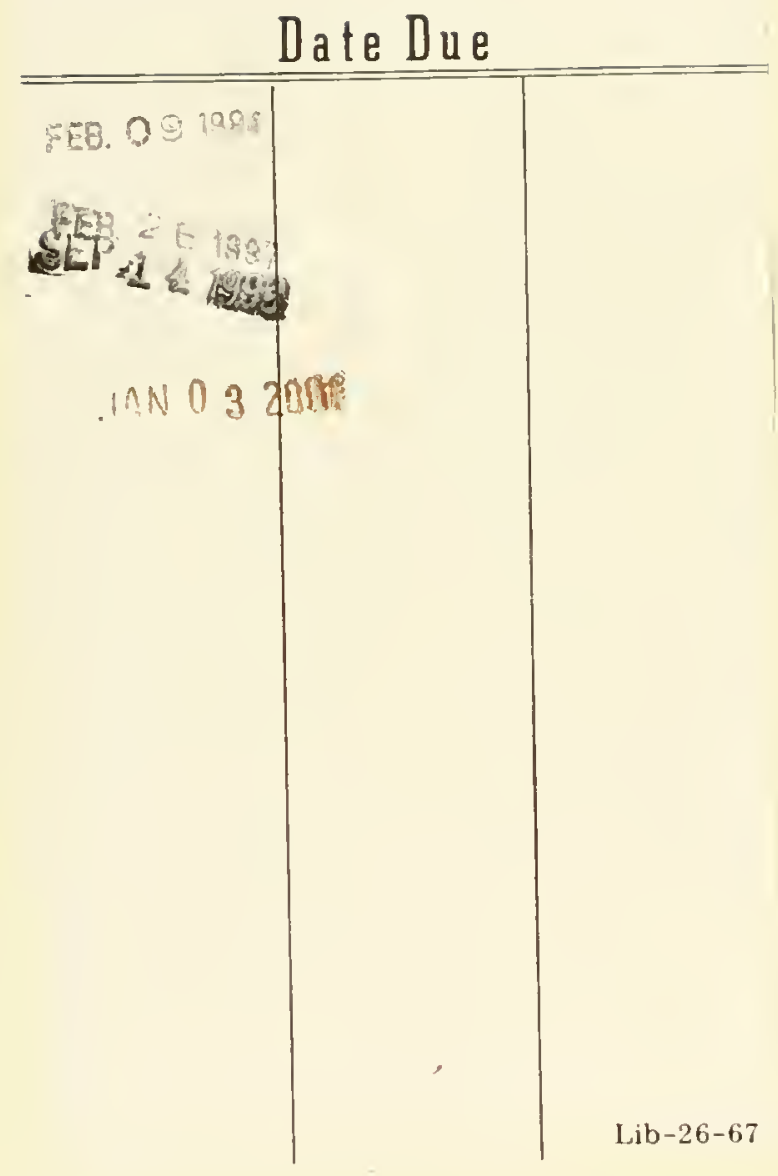



